indicates the difficulties in measuring infiltration in the field. Fergus and Hollowell give a good historical account of red clover and research in progress on it; this paper includes a good account of husbandry in the field.

Of the rest, the paper on "Agronomy in the Southwest United States" seems misnamed-it describes the agriculture of the area; the paper on grass and legume seed-production and testing omits all reference to the inoculation of legume seed, and in a long section on diseases dismisses bacteria, viruses and nematodes in one sentence.

G. V. DYKe

Flora of Peru

By J. Francis Macbride. (Botanical Series, Vol. 13, Part 5, No. 1.) Pp. 536+ii. (Chicago: Field Museum of Natural History, 1959.) 8.50 dollars.

R. MACBRIDE continues his Flora of Peru with 1 a volume devoted to the Araliaceae, Haloragaceae and a number of difficult gamopetalous families such as Ericaceae (including Vacciniaceae), Myrsinaceae, Ebenaceae, Gentianaceae, Apocynaceae and Convolvulaceae. The accounts of important genera such as Buddleia and Strychnos are also here. This work, as before, is a useful compilation as a basis for monographic work by specialists, and the author is an adept at pointing out the "interlocking characteristics" of the "species groups at present designated as genera" in some families. His numerous remarks in this vein force one to the conclusion that it is no good having 'specialists' in some of these families unless they have first-class brains and time for concentration on a wide survey over a long period. Mr. Macbride is old-fashioned enough to use the illegitimate name Erythraea for Centaurium, and he ignores the name Gentianella for a segregate genus covering the many Andine gentians, which he maintains in Gentiana. On p. 152, Samolus Valerandi, to which the South American S. floribundus Kunth is reduced, is unfortunately misprinted $S$. Verlanderi. N. Y. SANDWITH

\section{The Atomic Problem}

A Challenge to Physicists and Mathematicians. By Lancelot Law Whyte. Pp. 56. (London: George Allen and Unwin, Ltd., 1961.) 7s. 6d. net.

THE author calls for a drastic revision of the principles of physics in order to find answers to unsolved problems in that branch of science. In particular he wishes to retain the "principle of atomism" and to discard "linear co-ordinate systems, dimensional parameters, two-entity interactions and time-invariants". Many of his propositions could be interpreted in different ways, but there is an unambiguous demand for a theoretical deduction of the fine structure constant; there is also a clear request for including irreversibility in the basic laws of the new physics. While not attempting to substantiate his programme the author expresses the hope that others might follow his directives.

The fundamental principles of a science are due for revision if unsolved problems prove insoluble. In contemporary physics this situation does not arise : existing theories have neither spent their force nor are they tied to any rigid preservation of all their details. Current attitude to irreversibility belongs to the best secured domains of physics. The problem of the fine structure constant will attract more atten. tion than at present if it acquires any direct experimental implications. Perhaps the author believes that theoreticians are a complacent lot; they still continue to interpret new discoveries in terms of old theories unless incompatibility is clearly recognized. It would not be wise to prophesy now which of the author's propositions will materialize in a future revision.

R. EISENSCHITZ

\section{An Introduction to Infinitely Many Variates}

By Prof. Enders A. Robinson. (Griffin's Statistical Monographs and Courses, No. 6.) Pp. 132. (London: Charles Griffin and Co., Ltd., 1959.) $28 s$.

TWHE word 'Variates' in the title means 'random variables'. The first twenty pages give an account of probability theory as a normed measure over an abstract space. The next fifteen discuss limit theorems : followed by sixteen on Hilbert space and linear operators. These latter ideas are used in twenty pages on the spectral representation of stochastic processes and thirty pages on stationary processes. There is a large and useful collection of exercises. There is an extensive use of advanced mathematical ideas and notations, but practical problems are not entirely ignored (for example, section 7.9 on wavelet theory).

The monograph has been designed to give undergraduates an introduction to advanced techniques early in their statistical training. To my mind it is too condensed for this, and makes too many errors. Students at this level will not be familiar with the Radon-Nikodym theorem, and therefore will not know that it is stated wrongly on p. 13-nor the inversion theorem on p. 30-nor the definition of continuity on p. 19. But the book could be valuable for readers who can spot such mistakes and require a brief introduction to limit theorems and spectral analysis. The book would have been better had it been more carefully written and had it not been so curt, for the material is well organized. D. V. LINDLEY

\section{Chemistry of Carbon Compounds}

A Modern Comprehensive Treatment. Edited by Dr. E. H. Rodd. Vol. 4, Part C : Heterocyclic Compounds. Pp. xviii +1465-2201. (Amsterdam : Elsevier Publishing Company; London: D. Van Nostrand Company, Ltd., 1960.) 130s.

VITH Volume 4 of this work the section on heterocyclic compounds is complete and the whole project draws near to its conclusion. This volume continues the systematic treatment of six-membered ring systems containing two heteroatoms, proceeds to those with more than two and hence to seven-membered and larger heterocycles. Separate chapters present excellent accounts of azine dyes, of purines, of nucleosides and nucleotides and of pteridines. About half the volume is devoted to a survey of alkaloids, largely written by $\mathbf{A}$. $\mathbf{R}$. Pinder, with contributions by $K$. W. Bentley and G. F. Smith. They and the other contributors are to be congratulated on a high order of achievement. The more familiar terrain and the outer reaches of the subject are charted with competence and lucidity that belie the magnitude of the tasks involved.

This is no mere cataloguing, but a genuine appreciation and appraisal of the state of these chemical topics, close to the date of publication. Once again a team of authors and a redoubtable, indefatigable editor have put the world of organic chemists in their debt.
JAMES D. LoudoN 